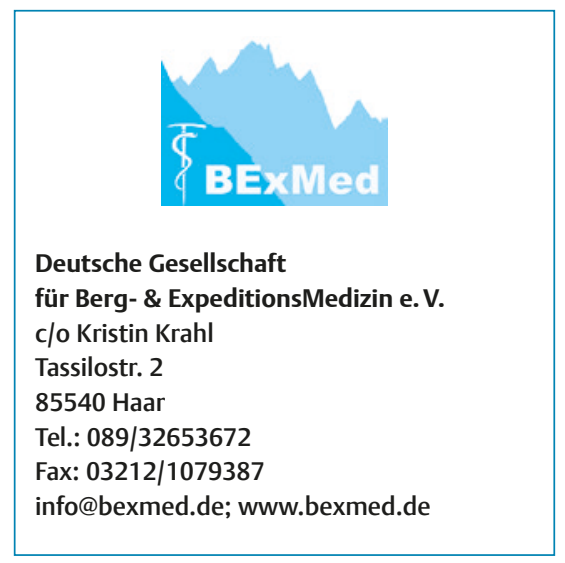

\section{Neue Adresse?}

Unser Anschreiben / unsere Mitteilungen / Zeitschriften wie FTR oder Rundbrief vom Anfang dieses Jahres haben leider nicht alle Mitglieder erhalten. Bitte melden Sie sich in der Geschäftsstelle, wenn es Änderungen in Ihrer Anschrift gab oder gibt, und Sie dieses Jahr noch nichts von der BExMed erhalten haben.

\section{Termine}

- $7^{\text {th }}$ European Hypoxia Symposium, Kührointalm bei Berchtesgaden, 19.-21.09.2014, www.hypoxiasymposium.org

- Jubiläumstagung zum 25-jährigen Bestehen der ÖGfAHM in Obergurgl: 07. -08.11.2014, www.bexmed.de/index.php/Tagungen.html

- Alpinmesse-Alpinforum Innsbruck, 22.-23.11.2014, Veranstalter: Österr. Kuratorium für Alpine Sicherheit, www.alpinmesse.info

\section{Förderpreis}

Auch für das laufende Jahr wird ein Förderpreis ausgeschrieben. Bewerbungsfrist ist der 31.12.2014. Näheres dazu finden Sie auf der Homepage.

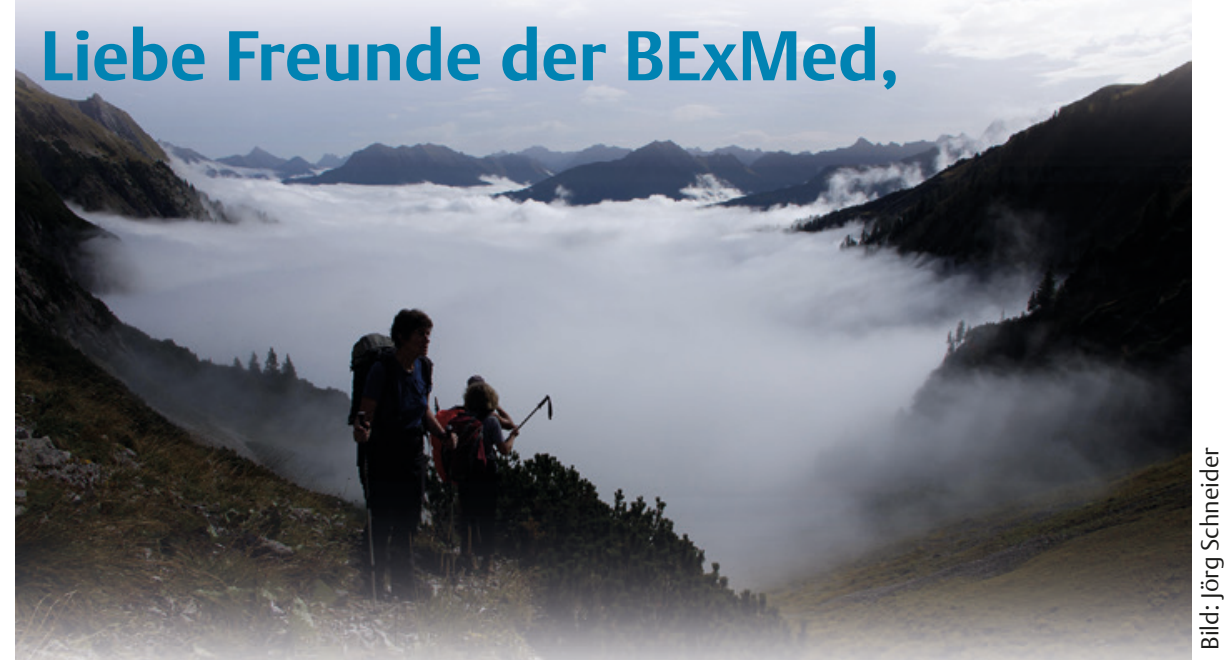

nach der Fußballweltmeisterschaft können wir uns nun wieder auch anderen Sportarten widmen.

\section{Kurse}

Wie versprochen kommt hier der Termin des nächsten Expeditionsärztekurses im Jahr 2015: Der Kurs findet im Wallis vom 11. bis 18. April 2015 statt. Näheres ist wie immer unter www.bexmed.de/index. php/Kurse.html zu finden.

Dort finden Sie auch Informationen zum Kurs Lawinenmedizin und Kälteschäden 2015, der vom 6. bis 10. Februar 2015 in St. Jodok am Brenner, Österreich stattfinden wird.

\section{Prüfungen}

Die Prüfungen zum Diploma in Mountain Medicine und zum Diploma in Wilderness and Expedition Medicine werden dieses Jahr im Rahmen der Jubiläumstagung zum 25-jährigen Bestehen der ÖGfAHM in Obergurgl abgenommen. (07.-08.11.2014). Details dazu finden Sie unter www.bexmed.de/index.php/Tagungen.html.

\section{World Congress on High Altitude Medicine and Physiology}

Dieser Kongress fand vom 25. bis 31. Mai in Bozen statt. Dort haben sich viele Freunde der Berg- und Höhenmedizin versammelt. Junge Forscher waren genauso mit ihren Forschungsergebnissen vertreten, wie die alten Hasen aus der Anfangszeit der höhenmedizinischen Forschung.

Für mich als langjährigen Beobachter der Szene hat sich bestätigt, dass die Erkenntnisse früherer Forscher immer noch Gültigkeit haben. So haben sich die Empfehlungen zu Aufstiegsgeschwindigkeit und Akklimatisation nicht wesentlich geän- dert. Auch die Empfehlungen zur Therapie der akuten Bergkrankheit sind im Wesentlichen unverändert. Die Forschung hat sich mehr auf die Ebene der Zellen und biochemischer Vorgänge verlagert.

Ein großes Diskussionsthema war Doping beim Höhenbergsteigen. Unter den Teilnehmer einer Podiumsdiskussion konnte kein Konsens erzielt werden, ob die Einnahme von Medikamenten zur besseren Akklimatisation ethisch vertretbar ist, ob dies unter Doping läuft oder ob es ,nur der Prophylaxe der akuten Bergkrankheit dient.

Insgesamt scheint Höhenbergsteigen ,sicherer' geworden zu sein. Dies liegt sicher nicht an den Fortschritten der Medizin, sondern mehr an besserem Training, leichterer und zuverlässigerer Ausrüstung sowie an zuverlässigen Wettervorhersagen. Schönwetterfenster können mit ausreichender Genauigkeit vorhergesagt werden, sodass der Gipfel bei bestem Wetter angegangen werden.

Im nächsten Heft werden wir in einem kurzen Überblick über den zweiten Teil des Kongresses berichten, bei dem es um das Thema Bergrettung ging.

Wir wünschen allen einen schönen Bergsommer und hoffen, einige von Ihnen in Obergurgl im November zu sehen.

Herzliche Grüße aus Kempten für den gesamten Vorstand

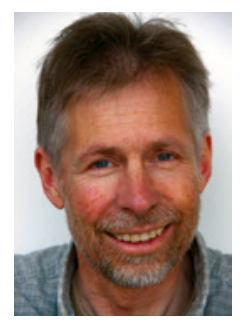

